\title{
HIDROGEOLOGIA DA BACIA HIDROGRÁFICA DO RIO ITAPICURÚ - BA, COMO SUBSIDIO PARA O PLANO DIRETOR DE BACIAS
}

Carlos Gleidson Campos da Purificação ${ }^{1}$; Raissa Santos Soares²; Marcelo Henrique de Jesus ${ }^{3}$; Lucas de

Queiroz Salles ${ }^{4}$; Thiago dos Santos Gonçalves ${ }^{5}$.

Resumo - A Bacia Hidrográfica do Rio Itapicuru situa-se na porção nordeste do Estado da Bahia, abrangendo 49 municípios, com área total de $37.345 \mathrm{~km}^{2}$. É limitada a norte pelos rios Real e Vaza Barris, a oeste pela Bacia do Rio São Francisco e a sul pelos rios Paraguaçu e Inhambupe. O propósito desse estudo é a caracterizar a hidrodinâmica e hidrogeoquímica dos diferentes sistemas aquífero que compõe a Bacia Hidrográfica do Rio Itapicuru, como ferramenta quer corrobora para o plano Diretor de Bacias. A partir de dados obtidos na Companhia de Engenharia Hídrica e de Saneamento da Bahia-CERB, foram elaborados, com auxílio do software QualiGraf (2014) disponibilizado pela Fundação Cearense de Meteorologia e Recursos Hídricos - FUNCEME e do software ArcGis 10.1, tabelas, gráficos e mapas. Para o estudo hidrogeológico da Bacia Hidrográfica do rio Itapicuru, essa foi dividida em dois grandes domínios, o primeiro, a oeste, correspondente as rochas de idade Arqueanas a Proterozoica do embasamento cristalino; o segundo, a leste, é representado por rochas Juro-Cretáceo da Bacia do Recôncavo.Com isso observou-se que o fluxo preferencial no sentido NW-SE subordinado localmente a um fluxo N-S em direção a calha do rio Itapicuru. Com relação a hidroquímica, as águas do aquífero poroso são classificadas, predominantemente como sódicas cloretadas, e cloretadas mistas para o aquífero fissural.

Palavras-Chave-Bacia do Rio Itapicuru; Hidroquímica; Hidrodinâmica.

ABSTRACT- The Basin Itapicuru Rio is located in the northeast portion of the state of Bahia, covering 49 municipalities, with a total area of $37,345 \mathrm{~km} 2$ is bounded on the north by Real and Vaza Barris rivers, to the west by River Basin and San Francisco the south by the Paraguaçu and Inhambupe rivers. The purpose of this study is to characterize the hydrodynamics and hydrochemistry of different aquifer systems that make up the River Basin Itapicuru as a tool or corroborates the Director of Watershed plan. From data obtained in the Society of Hydropower Engineering and Sanitation Bahia-CERB they were prepared with the aid of QualiGraf software (2014) provided by the Foundation Cearense for Meteorology and Water Management - FUNCEME and ArcGIS 10.1 software, tables, graphs and maps. For the hydrogeological study of Basin Itapicuru river, this was divided into two main areas, the first in the west, matching the old Archean rocks the Proterozoic crystalline basement; the second, to the east, is represented by rocks of Cretaceous swear to Recôncavo.Com Basin that observed that preferential flow in the NW-SE direction locally subordinate to a N-S flow towards the gutter Itapicuru. Regarding hydrochemistry, the porous aquifer waters are classified predominantly as sodic chlorinated, and mixed chlorinated for fissural aquifer.

${ }^{1}$ Estudante de Graduação em Geologia - Universidade Federal da Bahia, Núcleo de Estudos Hidrogeológicos e do Meio Ambiente - Nehma. Rua Barão de Geremoabo, s/n ${ }^{\circ}$ Campus Universitário de Ondina, CEP: 40.170-020, fone: (71) 32838637. carlos_cursos@ hotmail.com. 
2 Estudante de Graduação em Geologia - Universidade Federal da Bahia, Núcleo de Estudos Hidrogeológicos e do Meio Ambiente - Nehma. Rua Barão de Geremoabo, s/n Campus Universitário de Ondina, CEP: 40.170-020, fone: (71) 32838637. raissa.ufba@yahoo.com.br.

${ }^{3}$ Estudante de Graduação em Geologia. - Universidade Federal da Bahia, Núcleo de Estudos Hidrogeológicos e do Meio Ambiente - Nehma. Rua Barão de Geremoabo, s/n Campus Universitário de Ondina, CEP: 40.170-020, fone: (71) 32838637.

${ }^{4}$ Mestrando do Programa de Pós-Graduação em Geologia - Universidade Federal da Bahia, Núcleo de Estudos Hidrogeológicos e do Meio Ambiente - Nehma. Rua Barão de Geremoabo, s/n Campus Universitário de Ondina, CEP: 40.170-020, fone: (71) 32838637. Lucassales2008@ gmail.com.

${ }^{5}$ Mestrando do Programa de Pós-Graduação em Geologia - Universidade Federal da Bahia, Núcleo de Estudos Hidrogeológicos e do Meio Ambiente - Nehma. Rua Barão de Geremoabo, s/n Campus Universitário de Ondina, CEP: 40.170-020, fone: (71) 32838637. T.gon@ outlock.com.

\section{1. Área de Estudo}

A bacia do rio Itapicurú Localiza-se na porção nordeste do estado da Bahia entre as latitudes $10^{\circ}$ e $12^{\circ} \mathrm{S}$ e longitudes $41^{\circ}$ e $37^{\circ} \mathrm{W}$, ocupando uma área de $37.345 \mathrm{Km}^{2}$ e abrangendo na sua totalidade 49 municípios. É limitada a norte pelos rios Real e Vaza Barris, a sul com os rios Paraguaçú e Inhambupe, a oeste pela bacia do rio São Francisco e, a leste pelo oceano atlântico.

\subsection{Clima}

O clima influencia na infiltração através da disponibilidade de chuvas e na distribuição. $\mathrm{O}$ clima na bacia do rio Itapicurú varia de semiárido (de 7 a 8 meses secos) a úmido (subseco), como mostra o mapa da Figura 1. Nas regiões próximas a serra de Jacobina, a pluviosidade alcança até $1000 \mathrm{~mm}$ anuais e, nas regiões mais próximas a costa a pluviosidade pode atingir $1500 \mathrm{~mm} / \mathrm{ano}$. A região de menor pluviosidade consiste na porção central desta bacia, onde a pluviosidade varia de 400 a $600 \mathrm{~mm}$ anuais (Figura 2) e (Figura 3).

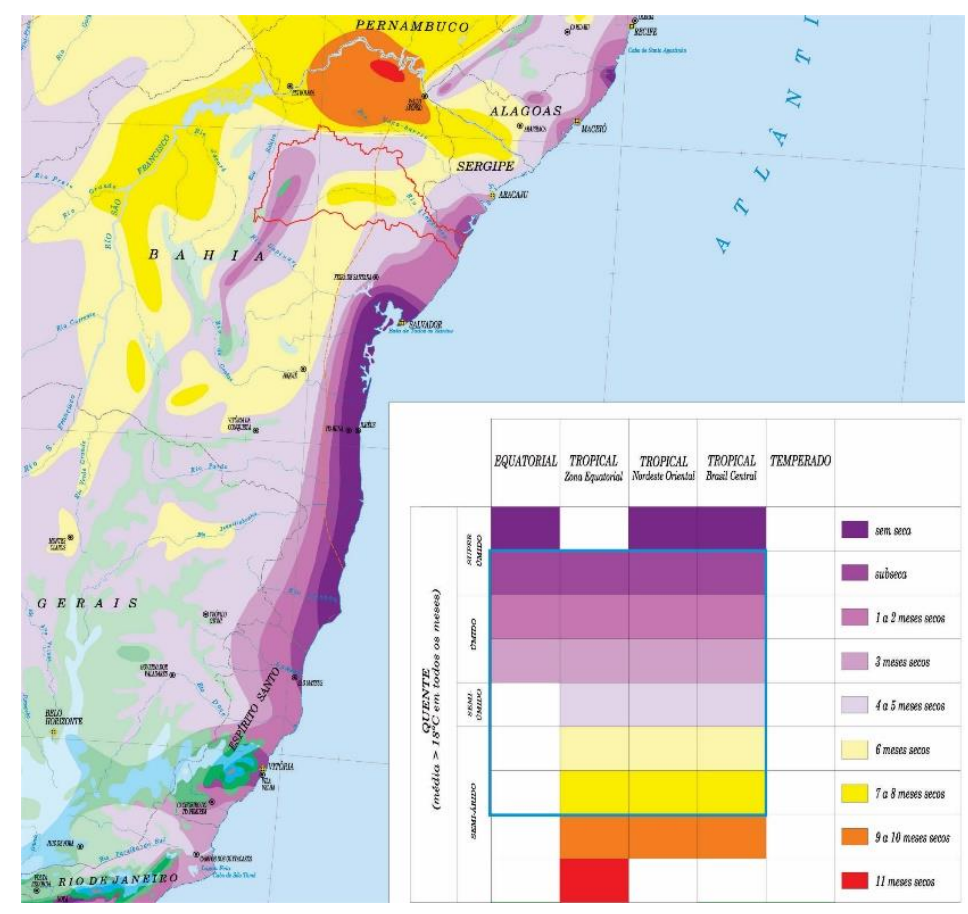

Figura 1: Adaptado do Mapa de Clima do Brasil. Fonte: IBGE, 2002. 


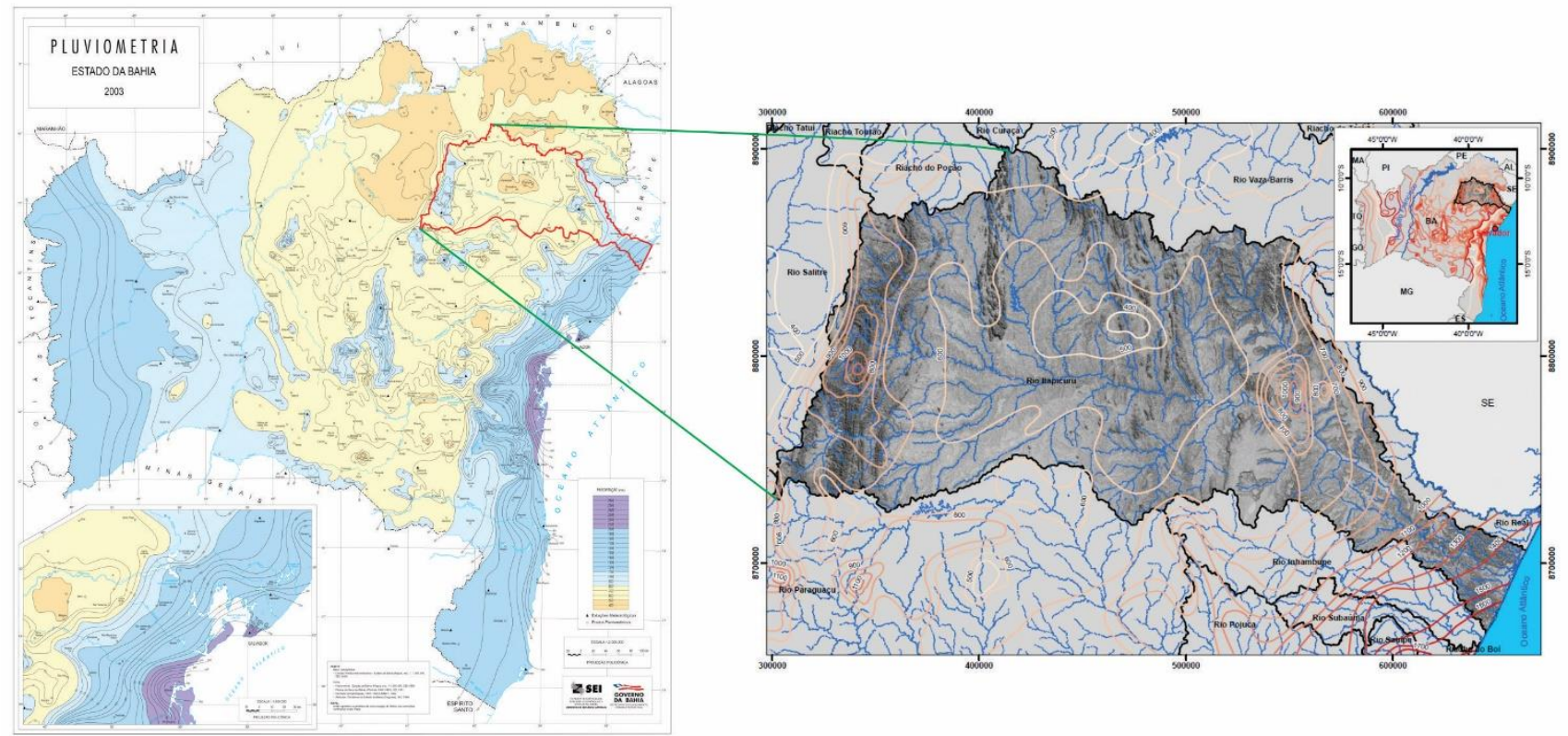

Figura 2: Adaptado do Mapa de pluviometria do Estado da Bahia e Mapa de Pluviosidade da Bacia do rio Itapicurú. Fonte: SEI, 2003.

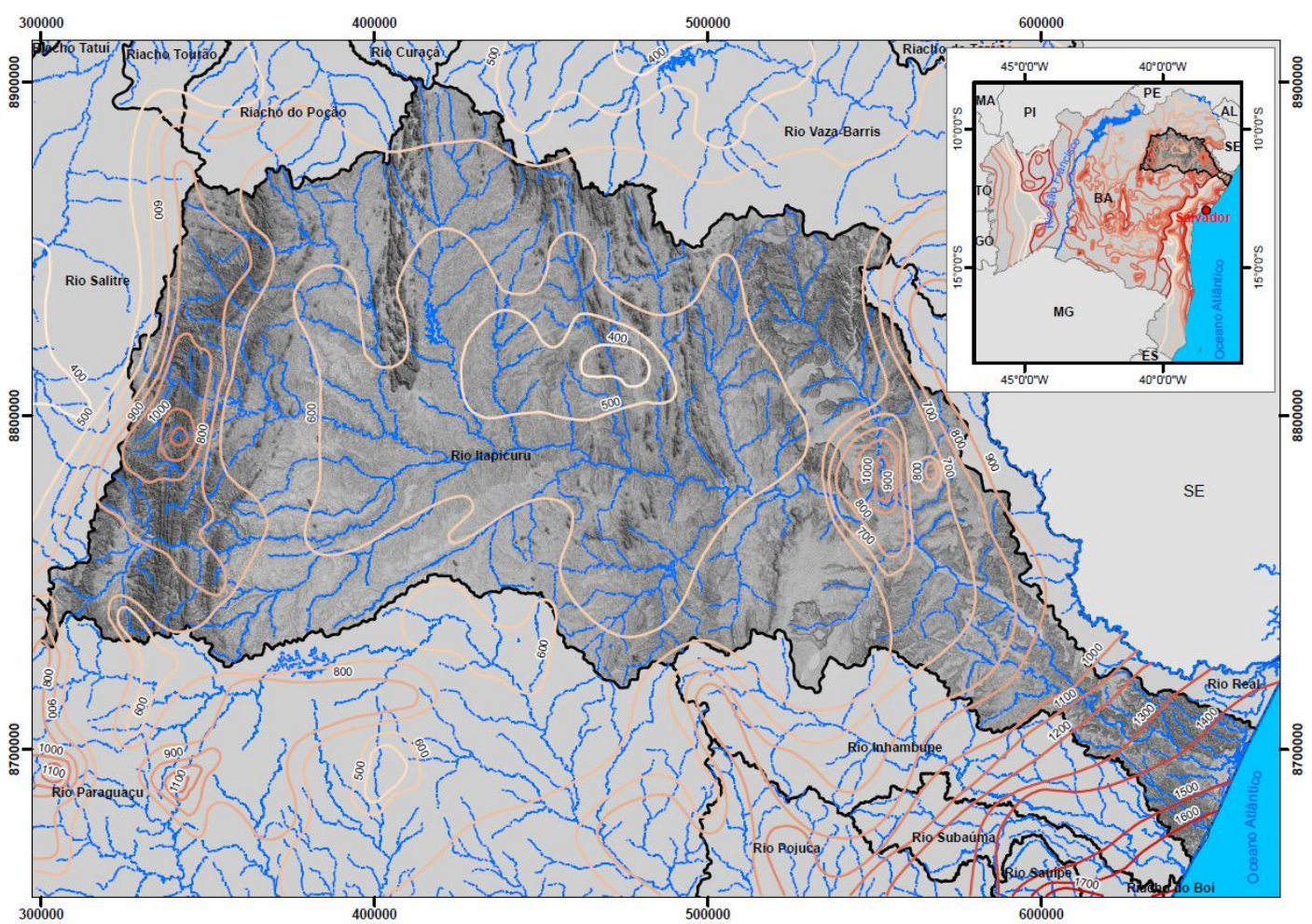

Figura 3: Mapa de Pluviometria da Bacia do rio Itapicurú. 


\subsubsection{Geomorfologia}

A geomorfologia é um elemento fisiográfico importante, pois suas diferentes configurações regulam a dinâmica da água em superfície, que por sua vez, contribui para elaboração da maioria das formas de relevo existentes. A geomorfologia controla o fluxo de água superficial e subterrâneo e, portanto influencia diretamente no regime de infiltração de água no terreno. Segundo Morais (2012) apud Berndtsson e Larson (1987), encostas convexas tendem a apresentar menores taxas de infiltração, enquanto que porções côncavas propiciam maior convergência dos fluxos superficiais, favorecendo o escoamento superficial, reduzindo portanto, a infiltração. Relevos com declividade alta tendem a apresentar maiores índices de infiltração de água no solo.

A geomorfologia da Bacia do rio Itapicurú é marcada predominantemente de Pediplanos retocados ou funcionais, que segundo o Radambrasil (1983), são caracterizados pelos Tabuleiros interioranos com altitudes em torno de $500 \mathrm{~m}$ e refletem interferências estruturais sobre o entalhamento dos canais, além dos Pediplanos Cimeiros e Sertanejos, Serras e Maciços Residuais, bem como Tabuleiros e formas de dissecação e aplainamento embutidos, relacionado às porções da Bacia do Recôncavo.

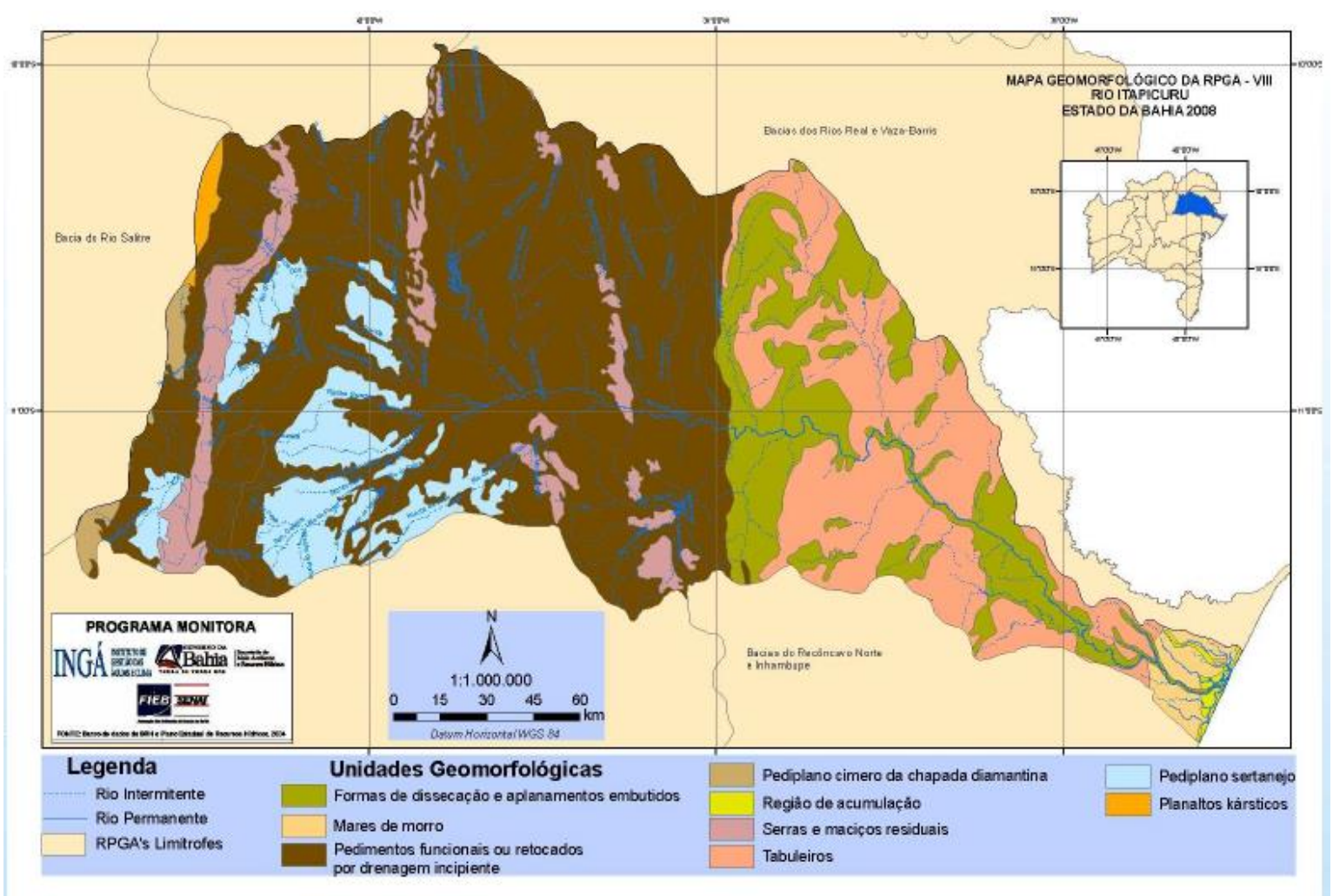


Figura 4: Mapa Geomorfológico da Bacia do Rio Itapicurú. Fonte: RPGA do Rio Itapicurú.

\subsubsection{Solos}

O solo constitui um fator importante no regime de infiltração da água em subsuperfície, essencial na recarga de aquíferos de modo geral. As características morfológicas como estrutura e textura do solo, influenciam diretamente na condutividade hidráulica (Morais, 2012). Porém, a primeira característica exerce maior controle sobre a segunda (Baird, 1997; Carvalho, 2002). Solos com estrutura em blocos subangulares e granulares tendem a ser os mais permeáveis.

As classes de solo que predominam na região segundo o RPGA da Bacia do rio Itapicurú, são as classes dos Planossolos, Latossolos e Argissolos, com ocorrência de Neossolos, Cambissolos, dentre outras classes.

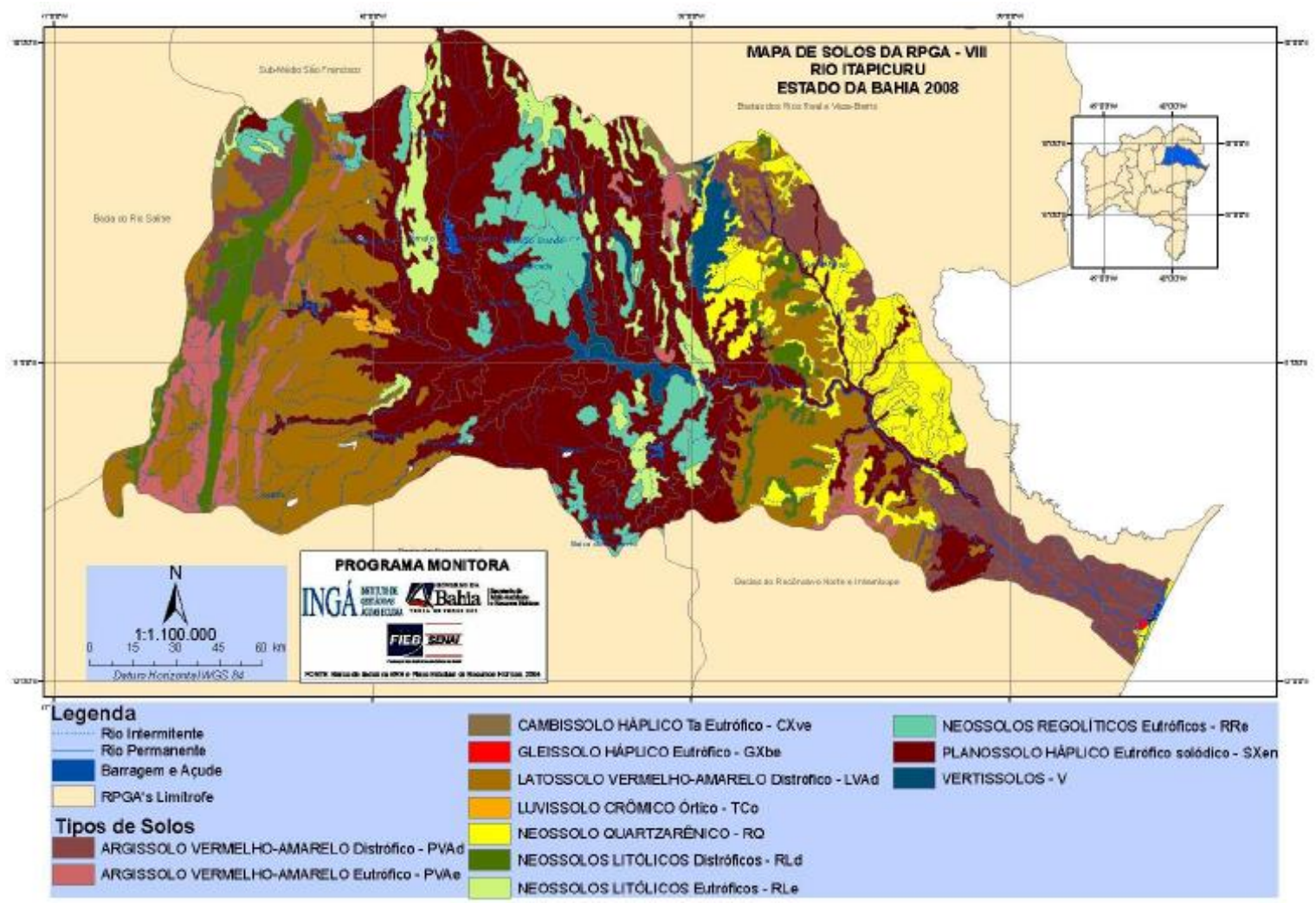

Figura 5: Mapa de solos da Bacia do rio Itapicurú. Fonte: RPGA do Rio Itapicurú.

\subsubsection{Vegetação}

A cobertura vegetal influencia na infiltração através da atenuação do impacto das gotas de água no solo, que é responsável pela quebra dos agregados estruturais do solo e reduz portanto a 
permeabilidade e favorece o escoamento superficial. A vegetação na Bacia do rio Itapicurú (Figura 4) é marcada predominantemente pela caatinga arbustiva, caatinga parque e campo rupestre, nas regiões dos pediplanos interioranos, com ocorrências da Floresta Estacional, nas porções serranas, formações pioneiras com influência fluviomarinha e vegetação secundária de Mata Atlântica nas regiões dos Tabuleiros costeiros (RPGA do rio Itapicurú; RadamBrasil, 1983).

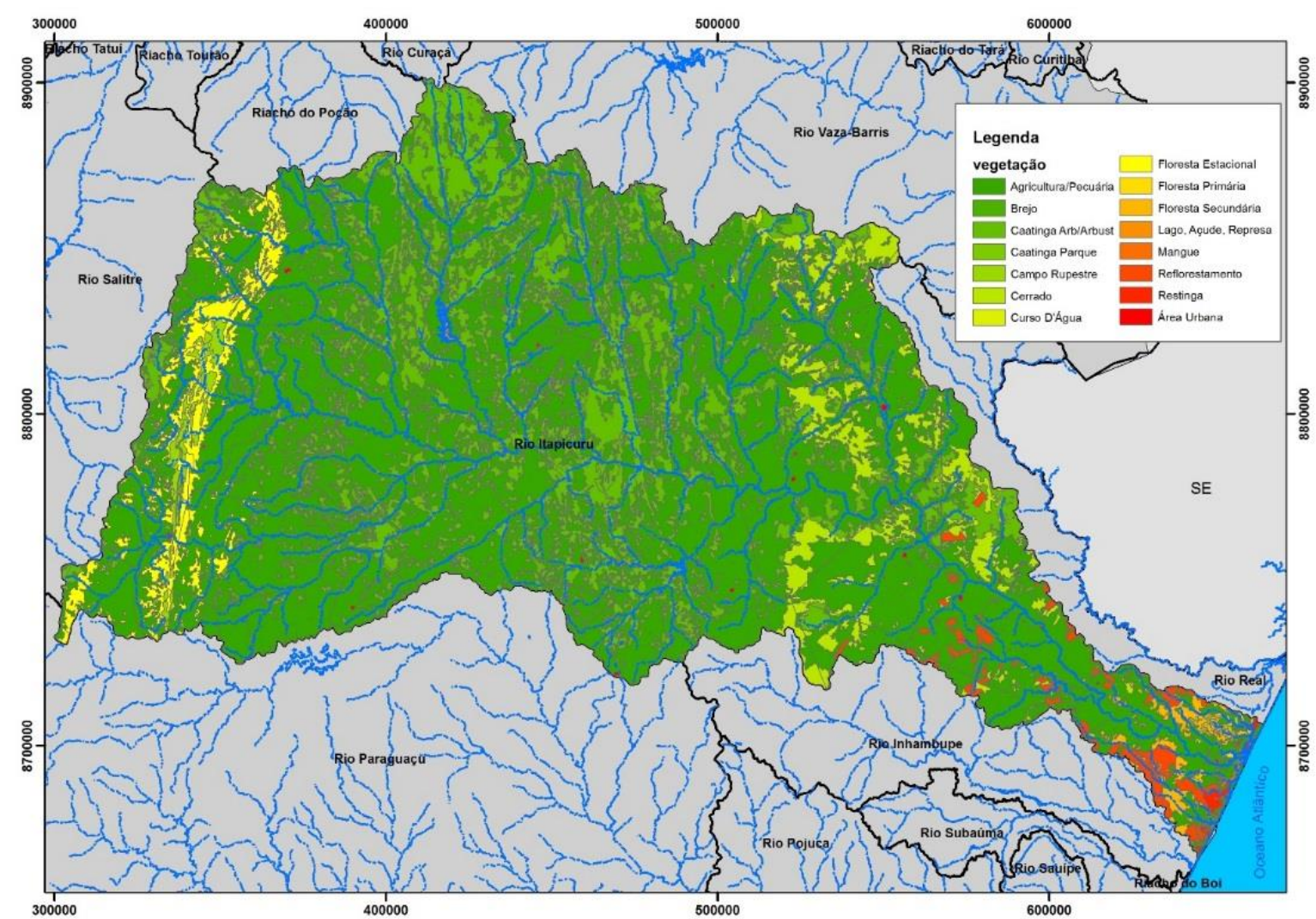

Figura 4: Vegetação da Bacia do Rio Itapicurú. Fonte: (SRH, 2003).

\subsubsection{Hidrografia}

A Bacia do rio Itapicurú é limitada ao norte pelos RPGAs do rio Real e do rio Vaza Barris, a oeste pela bacia do rio São Francisco, a sul pelas bacias do rio Paraguaçú e do rio Inhambupe. Os afluentes principais são os rios Itapicurú-mirim, Itapicurú Açú, rio do Peixe, rio Cariaçá, e rio Quijingue Figura . O rio Itapicurú nasce nos municípios de Miguel Calmon e Pindobaçú e desagua no município do Conde, no oceano atlântico. 


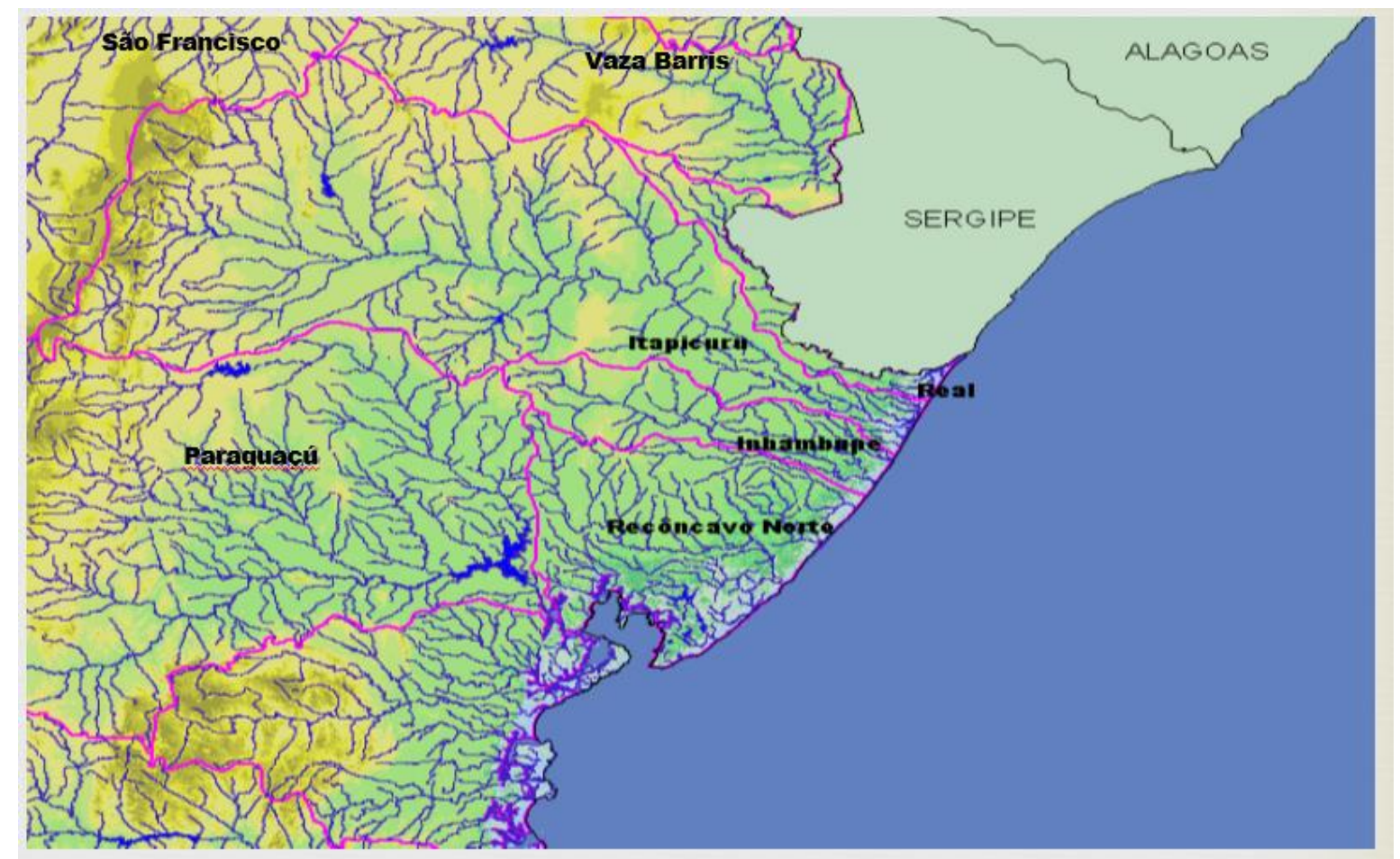

Figura 5: Bacias hidrográficas que fazem vizinhança com a bacia hidrográfica do rio Itapicurú. Fonte: (SRH/BAHIA, 2003).

\subsubsection{Geologia}

A geologia da bacia do rio Itapicurú pode ser dividida em três segmentos em função das características hidrogeológicas (Figura 6): 1)Domínio das Rochas do Embasamento, representado por Gnaisses TTGs Arqueanos, Granitóides, Intrusões Máficas e Ultramáficas e Rochas metassedimentares, de idades que variam desde o Arqueano ao Mesoproterozóico (Barbosa et al 2012), onde se hospedam os aquíferos fissurais; 2) Domínio da Bacia do Recôncavo, constituído por rochas sedimentares essencialmente siliciclásticas da fase de preenchimento de tal bacia (rifte e pós rifte), constituídas predominantemente por folhelhos e arenitos, do período Jurássico-Cretácio (Éon Fanerozóico) (Silva, 2007), como mostra a carta estratigráfica da Bacia do Recôncavo na Figura 7. Esta sedimentação tem sua origem relacionada ao rifte do Mesozóico, que culminou na abertura do oceano atlântico. Neste contexto de bacia desenvolvem se os aquíferos porosos. A Figura 8 mostra um perfil geológico esquemático da distribuição das formações geológicas e seus empilhamentos; 3) Domínio das coberturas e depósitos recentes, que são representados pelas coberturas tercioquaternárias do Grupo Barreiras, Formação Capim Grosso, ambas de natureza areno-argilosa e, coberturas detrito-lateríticas indiferenciadas, bem como os depósitos marinhos costeiros, fluviolagunares e transicionais, desenvolvendo também um sistema de aquífero poroso. Em cada 
um desses Domínios, desenvolve-se um arcabouço hidrogeológico com diferentes configurações e características, em função da natureza e estruturação dos litotipos presentes.

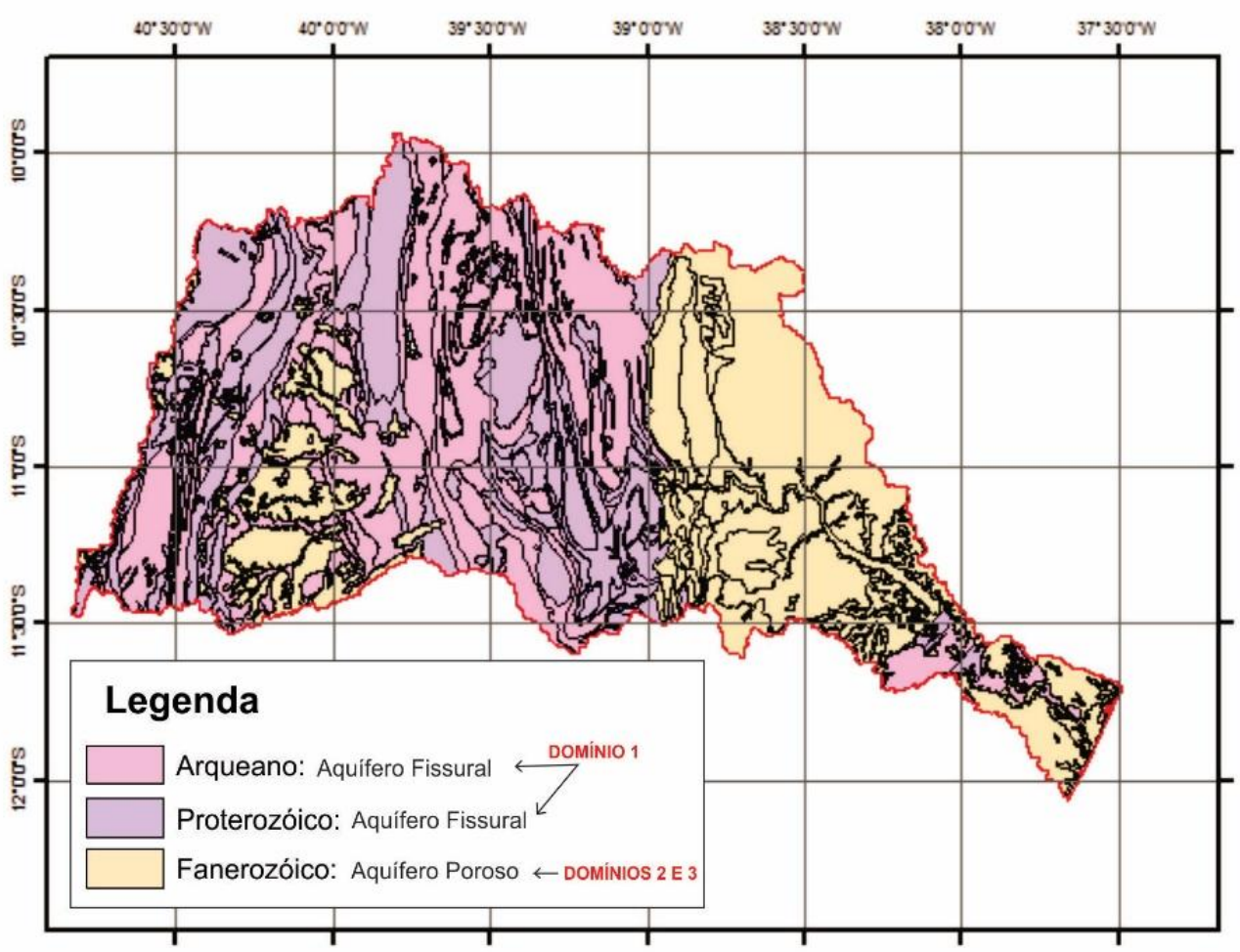

Figura 6: Mapa Geológico mostrando os Domínios Litológicos.

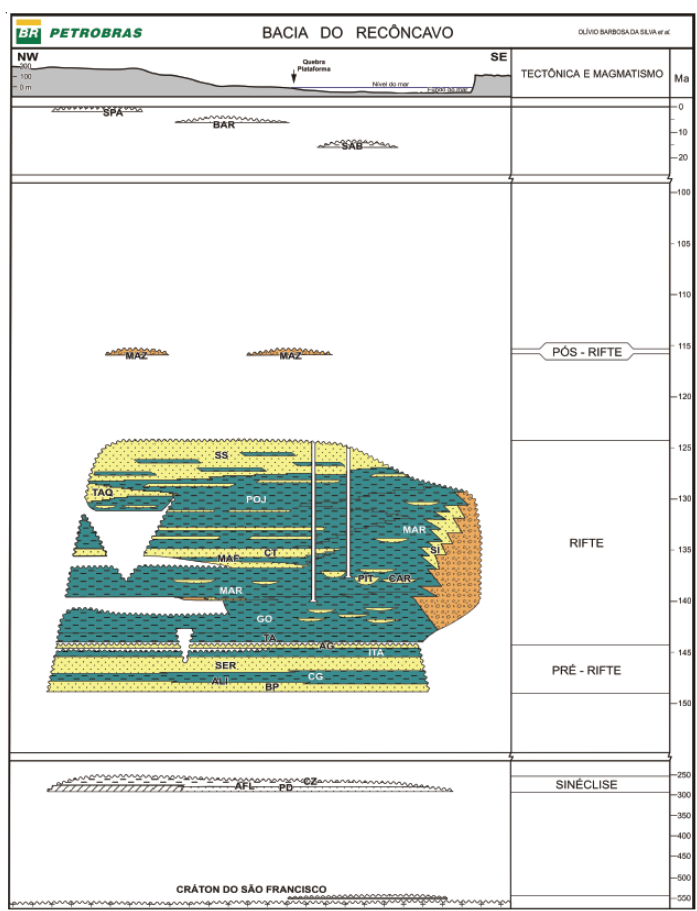

Figura 7: Carta estratigráfica da Bacia do Recôncavo. Fonte: Silva, 2007. 


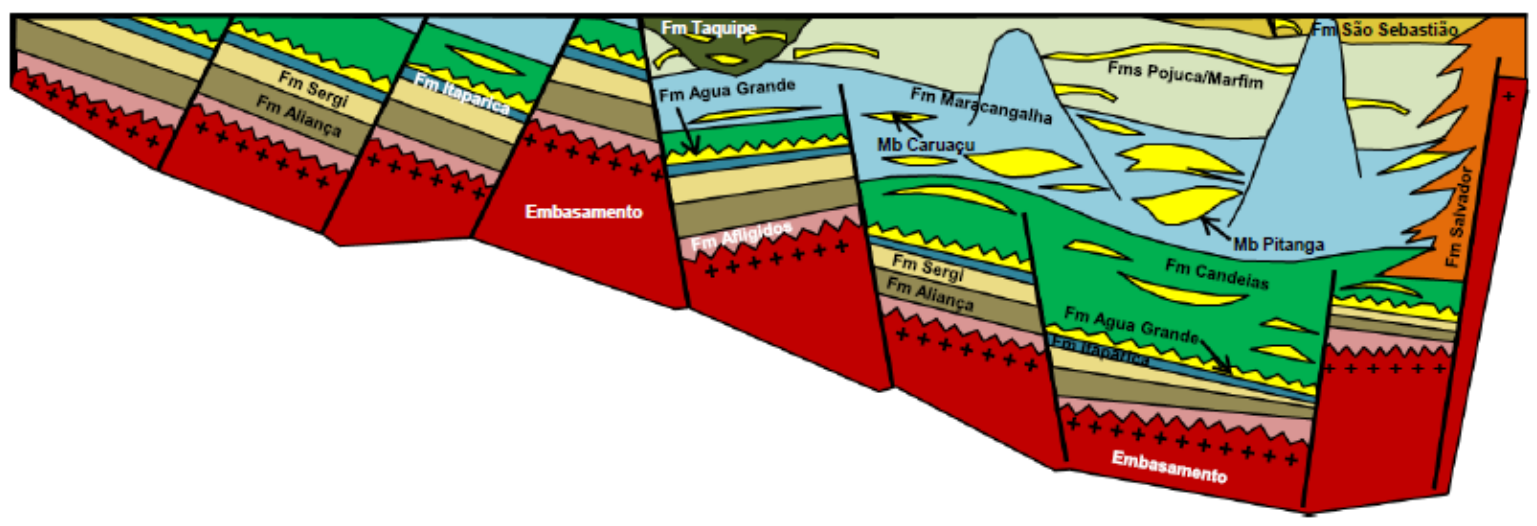

Figura 8: Perfil esquemático da Bacia do Recôncavo. Fonte: Fernandes, 2013.

\section{Aspectos Hidrodinâmicos}

Para essa análise a Bacia Hidrográfica do rio Itapicuru foi dividida em dois grandes domínios, o primeiro, a oeste, correspondente as rochas de idade Arqueanas a Proterozoica do embasamento cristalino; o segundo, a leste, é representado por rochas Juro-Cretáceo da Bacia do Recôncavo.

A partir do cálculo de carga hidráulica foi possível sugerir o fluxo subterrâneo na região. Como pode-se perceber, na Figura 9, o fluxo apresenta-se convergente para a calha central do rio Itapicuru, com altos piezométricos localizados preferencialmente nas bordas da bacia. Com isso, temos um fluxo preferencial NW-SE, subordinado, localmente, a um fluxo N-S, em direção a calha do rio. 


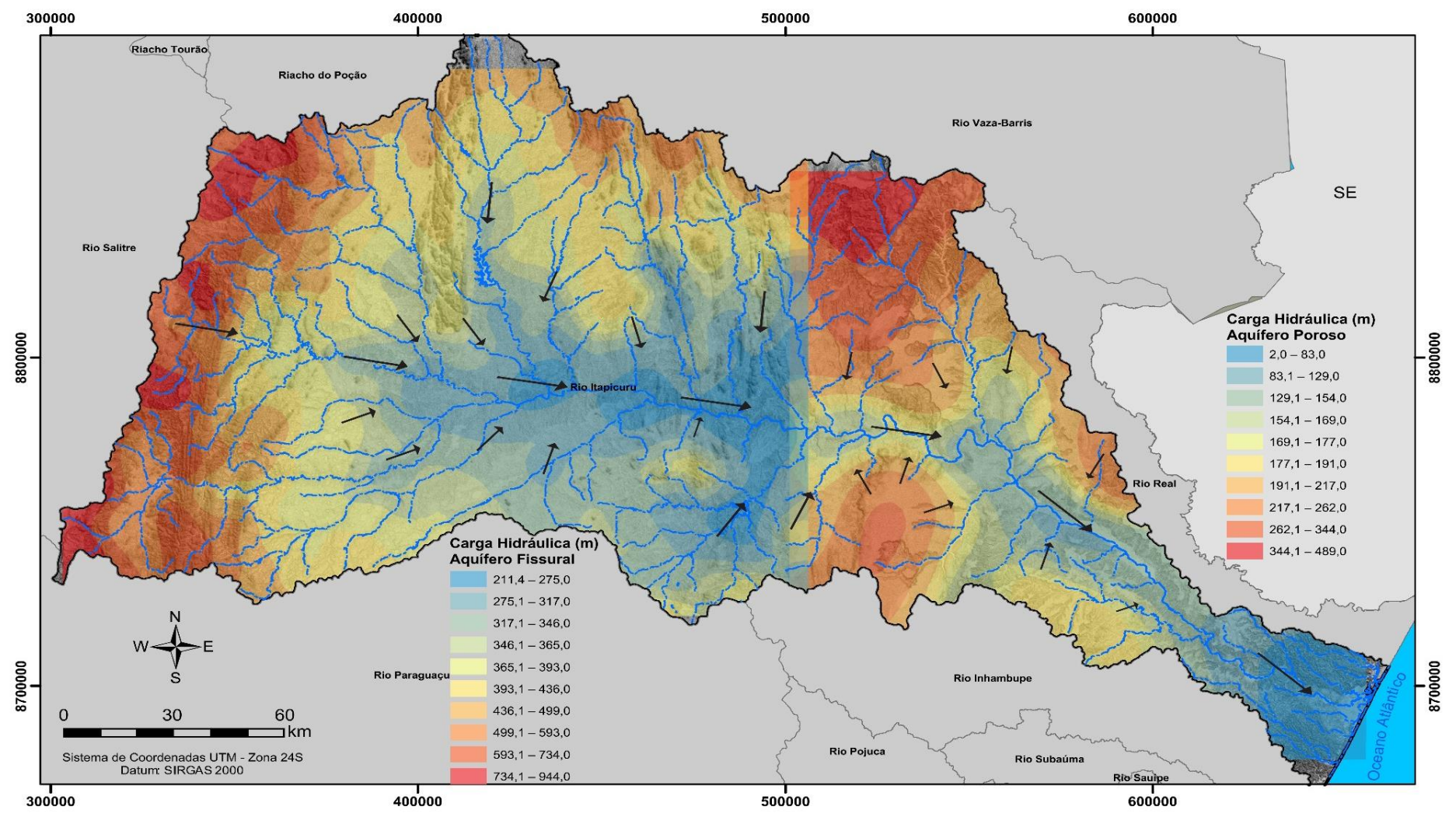

Figura 9: Mapa piezométrico da Bacia Hidrográfica do Rio Itapicuru.

Para um melhor entendimento das características hidráulicas dos aquíferos foram espacaializados (Figura 10) os dados de capacidade específica $\left(\mathrm{m}^{3} / \mathrm{h} / \mathrm{m}\right)$, visto que esse parâmetro melhor replete sua produtividade. Segundo Oliveira (2009) a capacidade específica faz parte do conjunto de indicadores importantes para o gerenciamento dos recursos hídricos subterrâneo. 


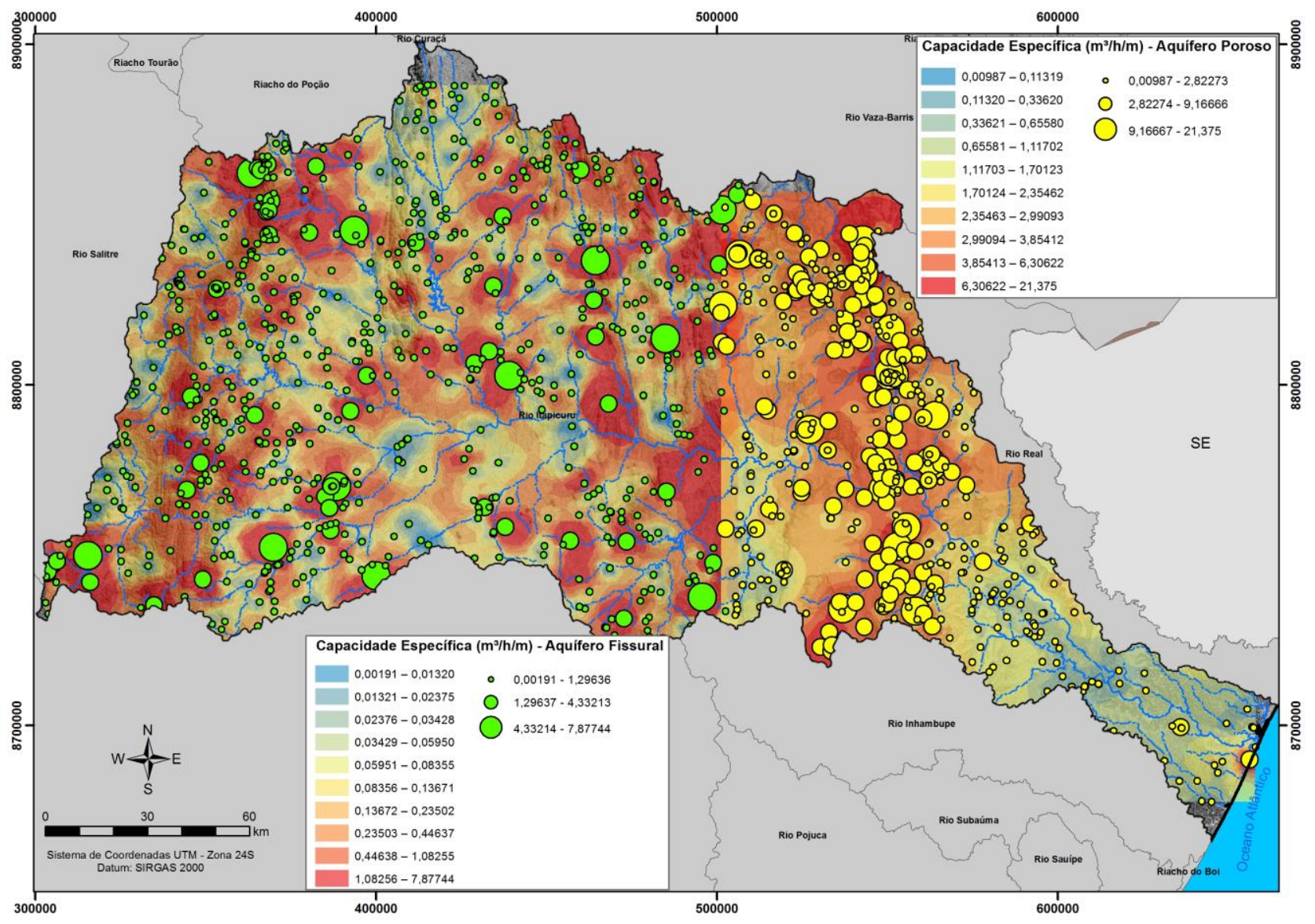

Figura 10: Distribuição especial da Capacidade Específica na Bacia Hidrográfica do Rio Itapicuru.

Os valores de capacidade específica são bastante distindos no dois domínios. No domínio fissural esses valores variam entre 0,0019 a 1 , sem um controle aparente na produtividade. Já no domínio sedimentar os valores de capacidade específica encotrados foram mais expressivos, variando de 0,0098 a 21,375. É possível observar uma faixa, com alinhamento N-S, na parte central desse domínio, onde encontram-se elevador valores pra a capacidade específica.

\section{Hidrogeoquímica}

Para estudo hidrogeoquímico da Bacia do Rio Itapicuru será utilizado a mesma divisão proposta na análise dos Aspectos Hidrodinâmicos supracitada. 
Para uma melhor compreensão dos resultados referentes à composição química das amostras analisadas, foram plotados os valores obtidos no diagrama triangular Piper (1944) (Figura 11).

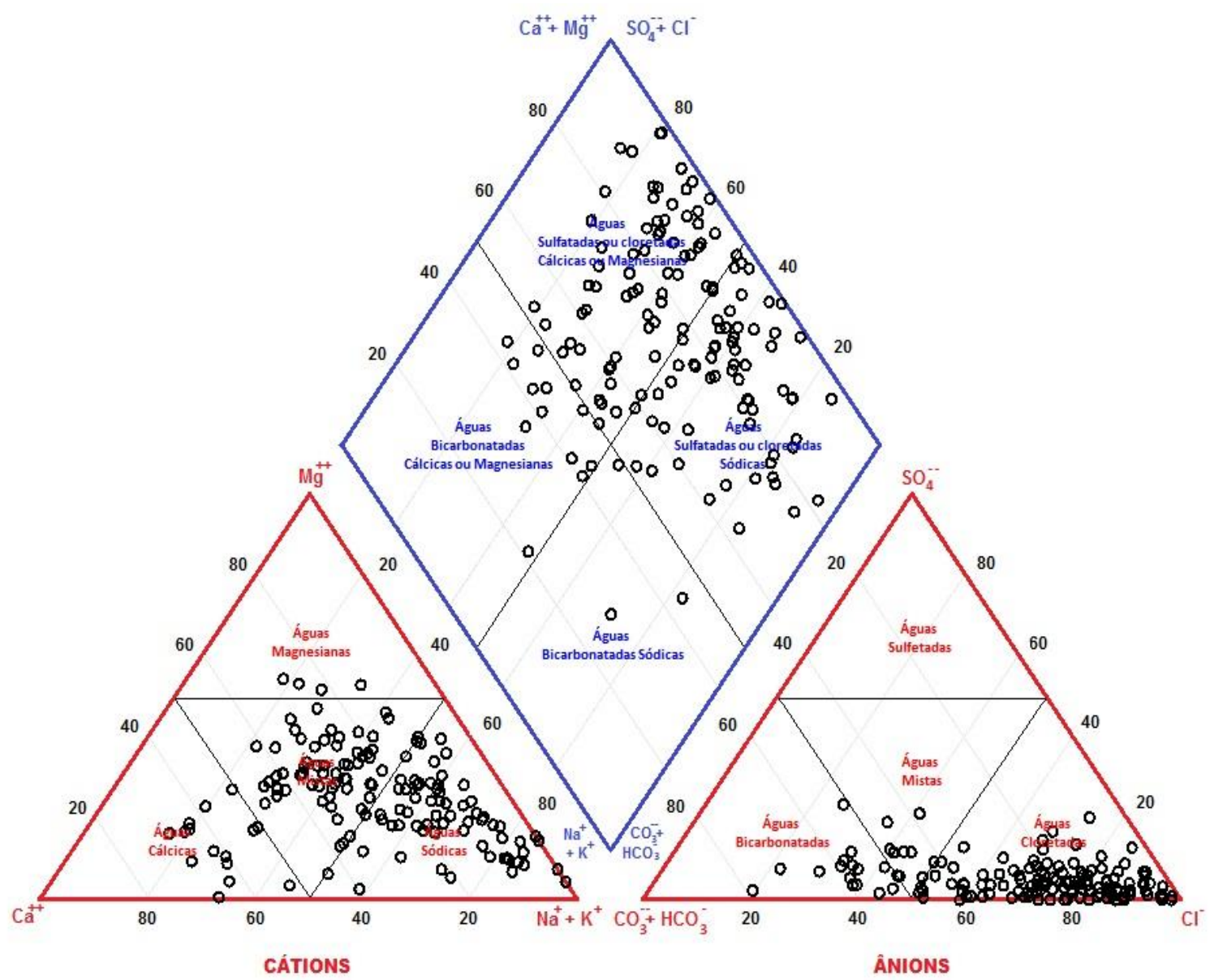

Figura 11: Classificação das águas em estudo segundo Piper (1944).

Os valores analíticos dos elementos maiores obtidos permitiram classificar as águas, como: Sódicas Cloretadas (41\%); Cloretadas Mistas (32\%); Cálcicas Cloretadas (6\%); e por fim Bicabornatadas Mistas (6\%). Foi possível observar uma evolução química das águas de Bicarbonatada para Cloretada (Figura 12) 


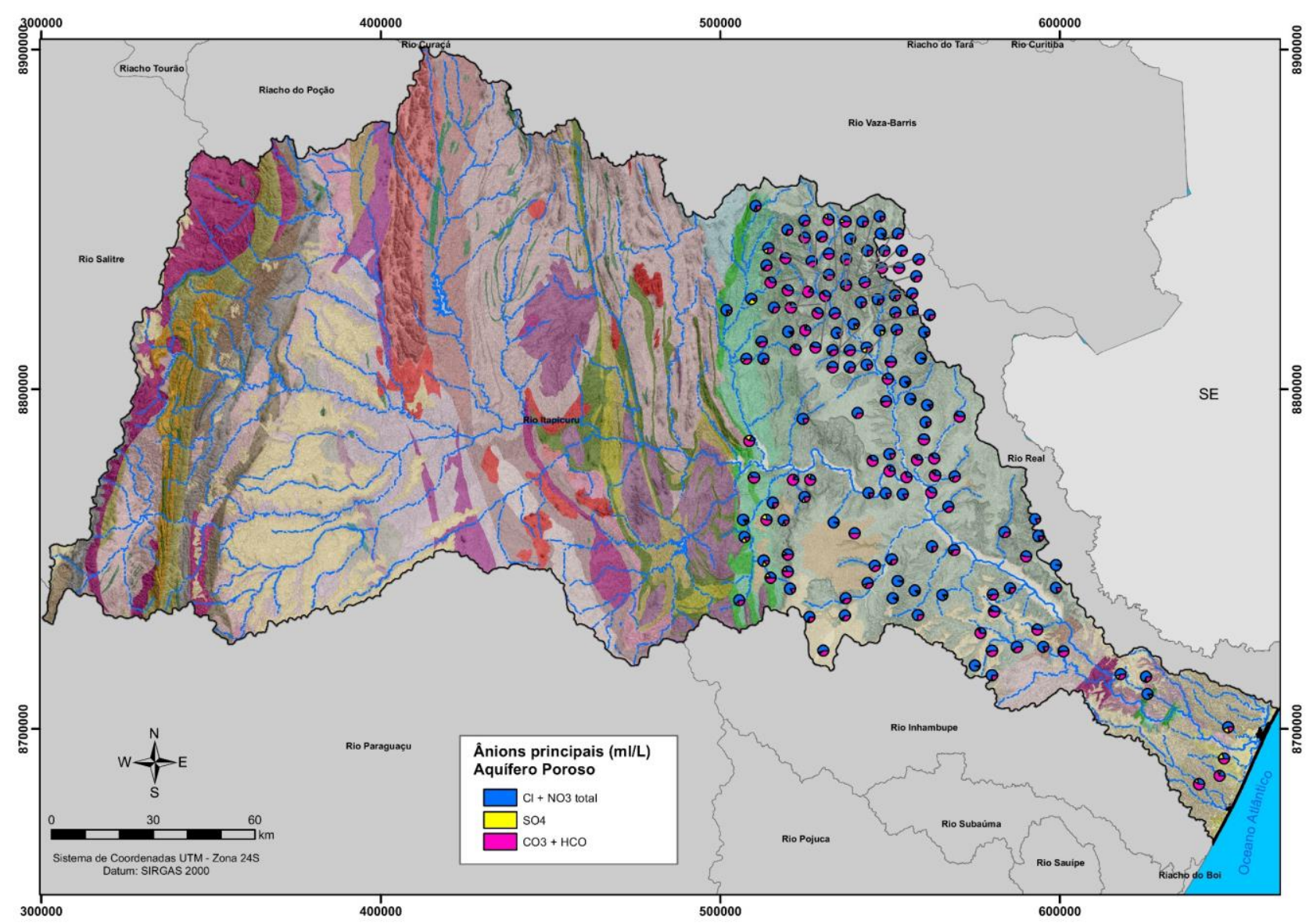

Figura 12: Distribuição dos principais ânions na Bacia Hidrográfica do Rio Itapicuru.

\subsubsection{STD - Salinidade das Águas Subterrâneas}

Os sólidos totais dissolvidos (STD) correspondem ao peso total dos constituintes inorgânicos e orgânicos adsorvidos por unidade de volume. Segundo a Resolução do Conselho Nacional do Meio Ambiente (CONAMA) 357/2005, com base no STD as águas podem ser divididas entre doces, salobras e salinas de acordo com as definições exemplificadas na tabela 1 abaixo.

Tabela 1: Classificação para salinidade segundo a Resolução do Conselho Nacional do Meio Ambiente (CONAMA) 357/2005.

\section{CLASSIFICAÇÃO QUANTO A SALINIDADE}

\begin{tabular}{l|c} 
Doce & $0-500$ \\
Salobra & $501-1500$ \\
Salgada & $>1500$
\end{tabular}


Segundo esta Resolução, as águas em estudo foram classificadas como águas doces (77,5\%), águas salobras $(15,2 \%)$ e águas salgadas (7,3). (Figura 13), especializados na figura 14.
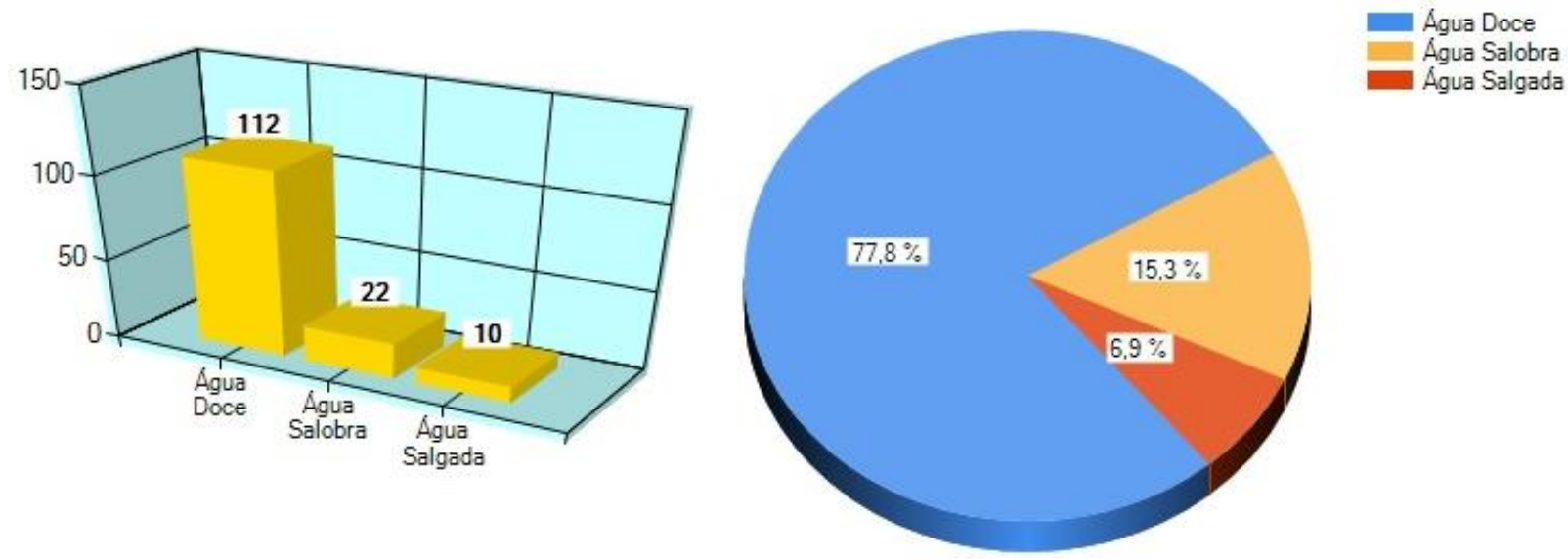

Figura 13: Classificação das águas em estudo segundo a Resolução do Conselho Nacional do Meio Ambiente (CONAMA) 357/2005 para salinidade.

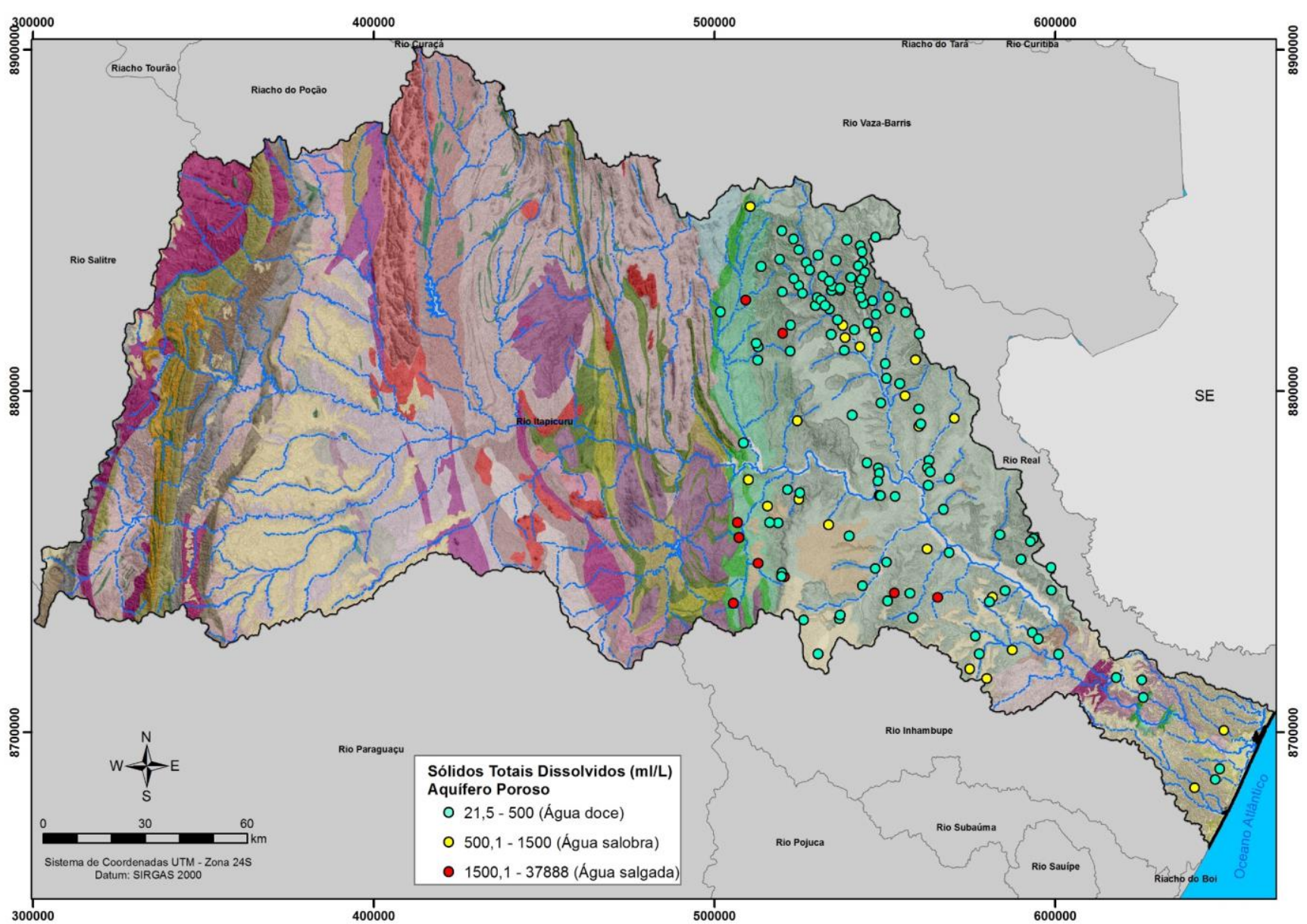

Figura 14: Distribuição espacial do STD na Bacia Hidrográfica do rio Iapicuru. 


\subsubsection{Diagrama de Lemoine (1954)}

A qualidade da água para irrigação é avaliada não apenas pelo seu conteúdo total de sais, mas também, pela composição individual dos íons presentes. Alguns cátions e ânions, quando em excesso, podem trazer prejuízos ao solo (pelo efeito direto na sodificação) e às plantas cultivadas, dependendo do grau de tolerância destas aos sais (AYERS e WESTCOT, 1991 apud por ÍTALO NUNES SILVA et al.,2011)

Nessa etapa, foi avaliado a Razão de Adsorção de Sódio - SAR, versus a Condutividade Elétrica - CE, como se segue na figura 15.

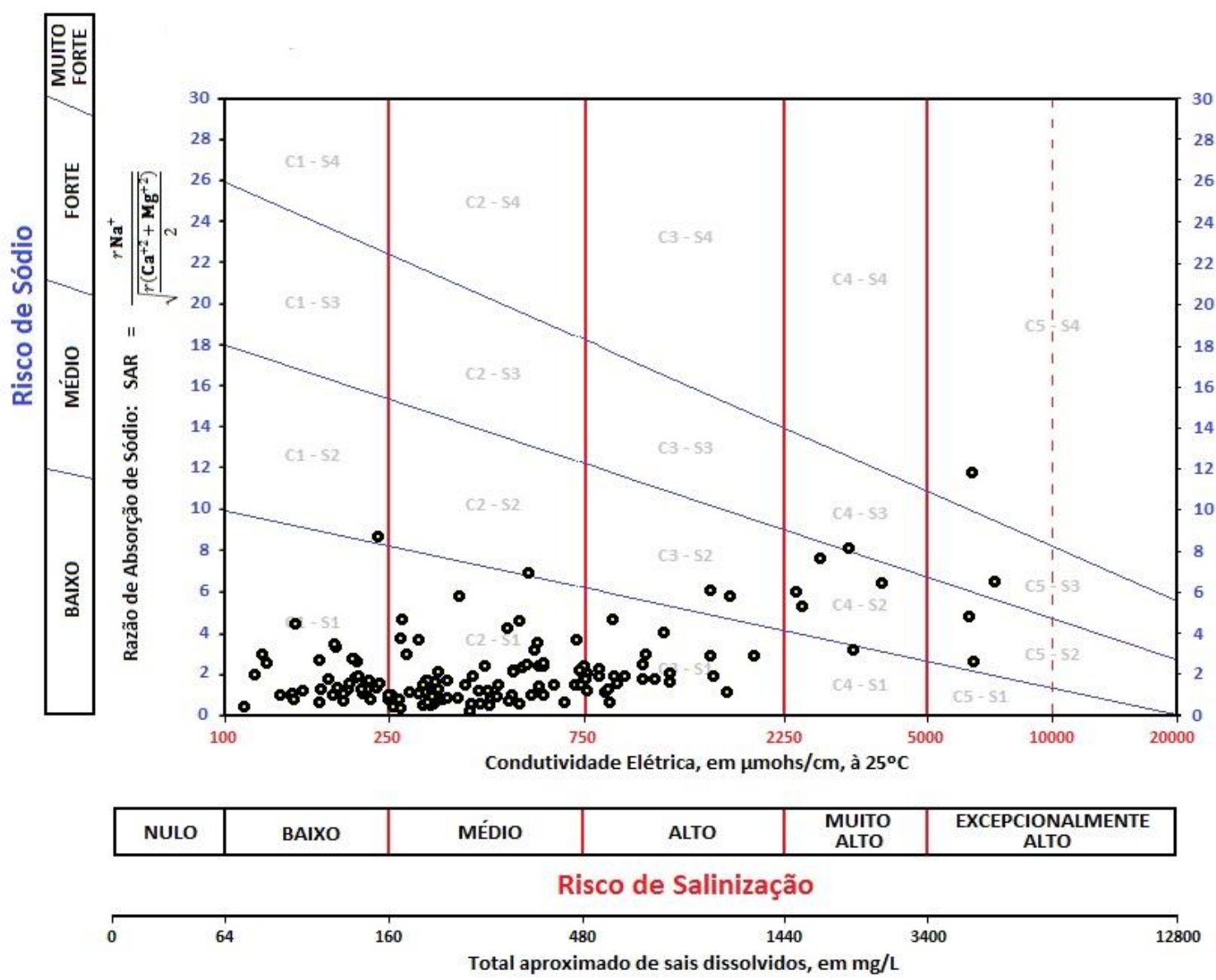

Figura 15: Classificação das águas para irrigação, segundo diagrama de Lemoine (1954). 
Para uma melhor compreensão dos resultados referentes à composição química das amostras analisadas, foram plotados os valores obtidos no diagrama triangular Piper (1944) (Figura 16).

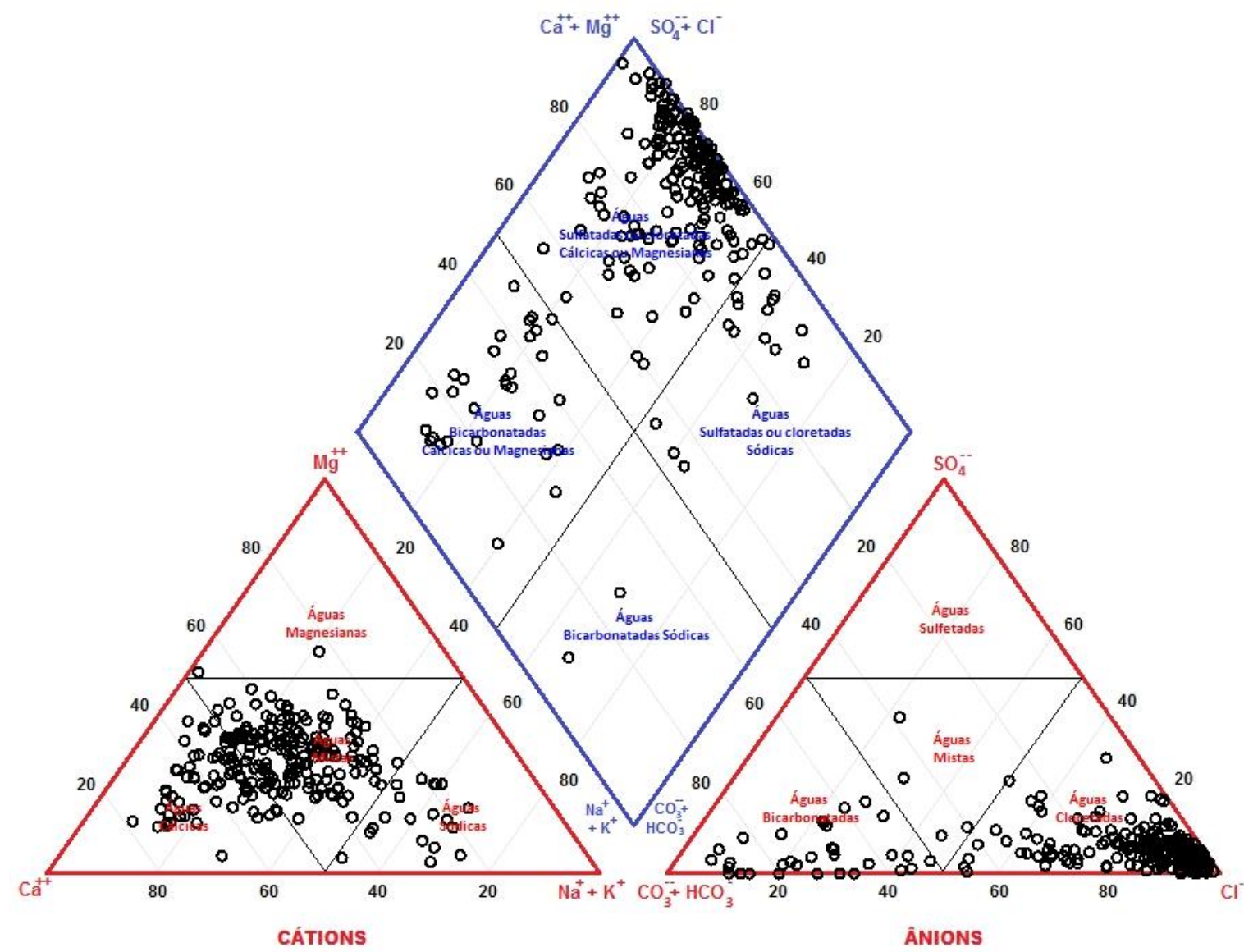

Figura 16: Classificação das águas em estudo segundo Piper (1944).

Os valores analíticos dos elementos maiores obtidos permitiram classificar as águas, como: Cloretadas Mistas (57\%); Cloretadas Cálcicas (20\%); Bicabornatadas Cálcicas (9\%); e por fim Cloretadas Sódicas (7\%). Foi possível observar uma evolução química das águas de Bicarbonatada para Cloretada (Figura 17). Observa-se que na região da Serra de Jacobina, as águas são mais bicarbonatadas, devido a interação com o tipo de rocha, e com uma pluviometria em torno de 900 a $1000 \mathrm{~mm}$, maior que no restante do domínio. 


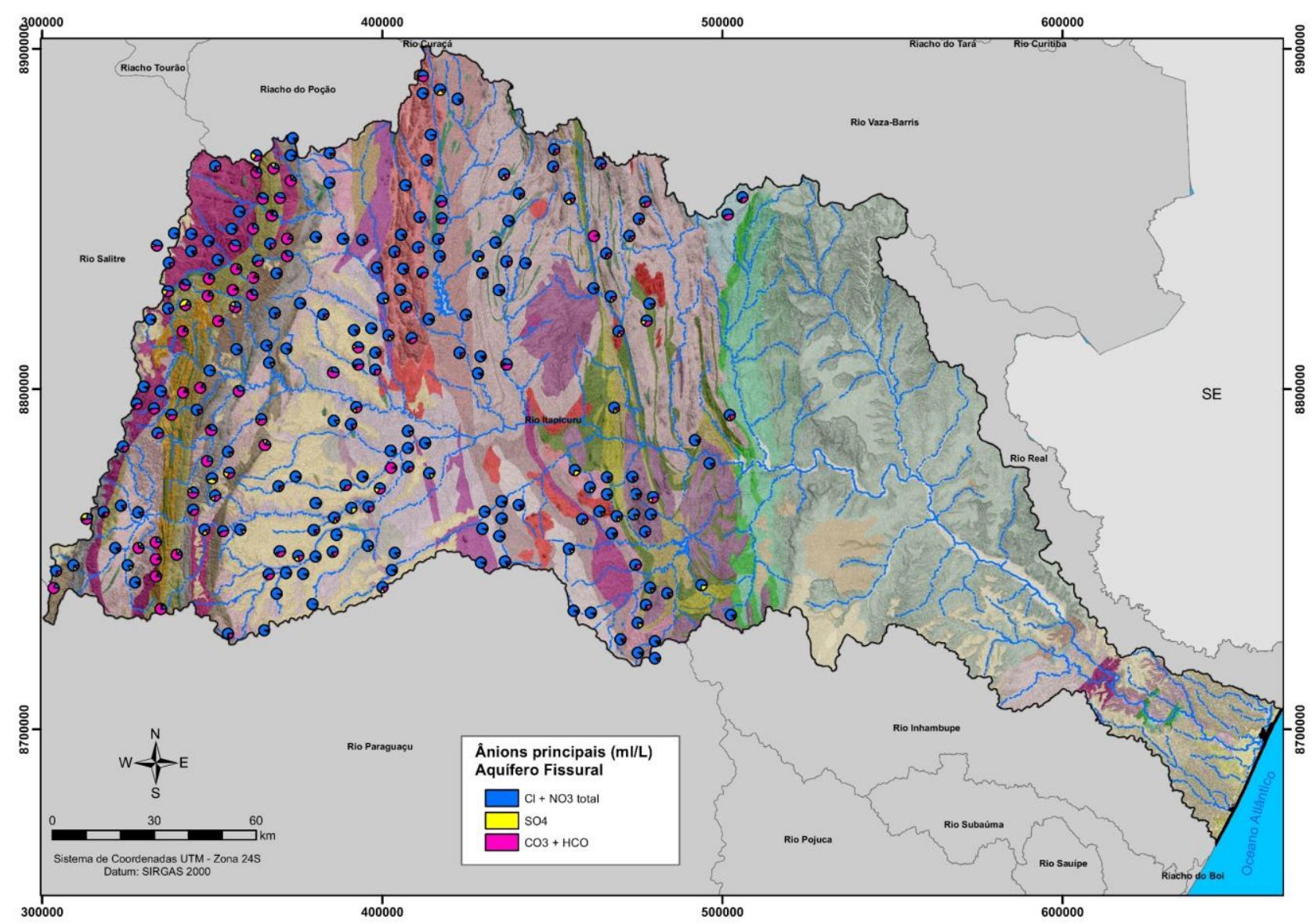

Figura 17: Distribuição dos principais ânions na Bacia Hidrográfica do Rio Itapicuru.

\subsubsection{STD - Salinidade das Águas Subterrâneas}

Segundo esta Resolução, as águas em estudo foram classificadas como águas doces $(19,1 \%)$, águas salobras (10,0\%) e águas salgadas (70,9). (Figura 18), espacializados na figura 19.
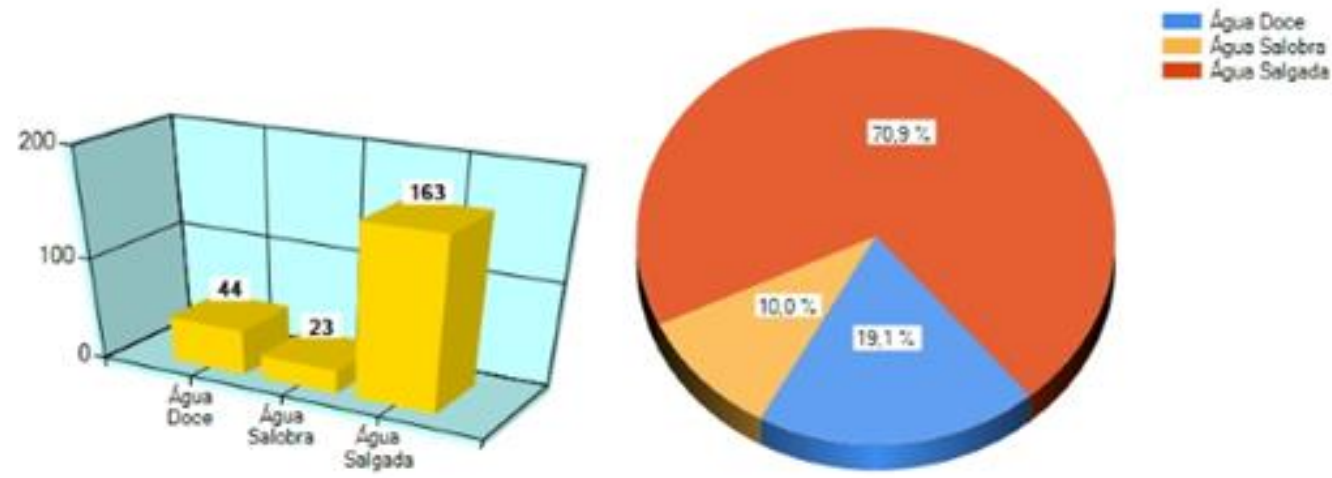
Figura 18: Classificação das águas em estudo segundo a Resolução do Conselho Nacional do Meio Ambiente (CONAMA) 357/2005 para salinidade.

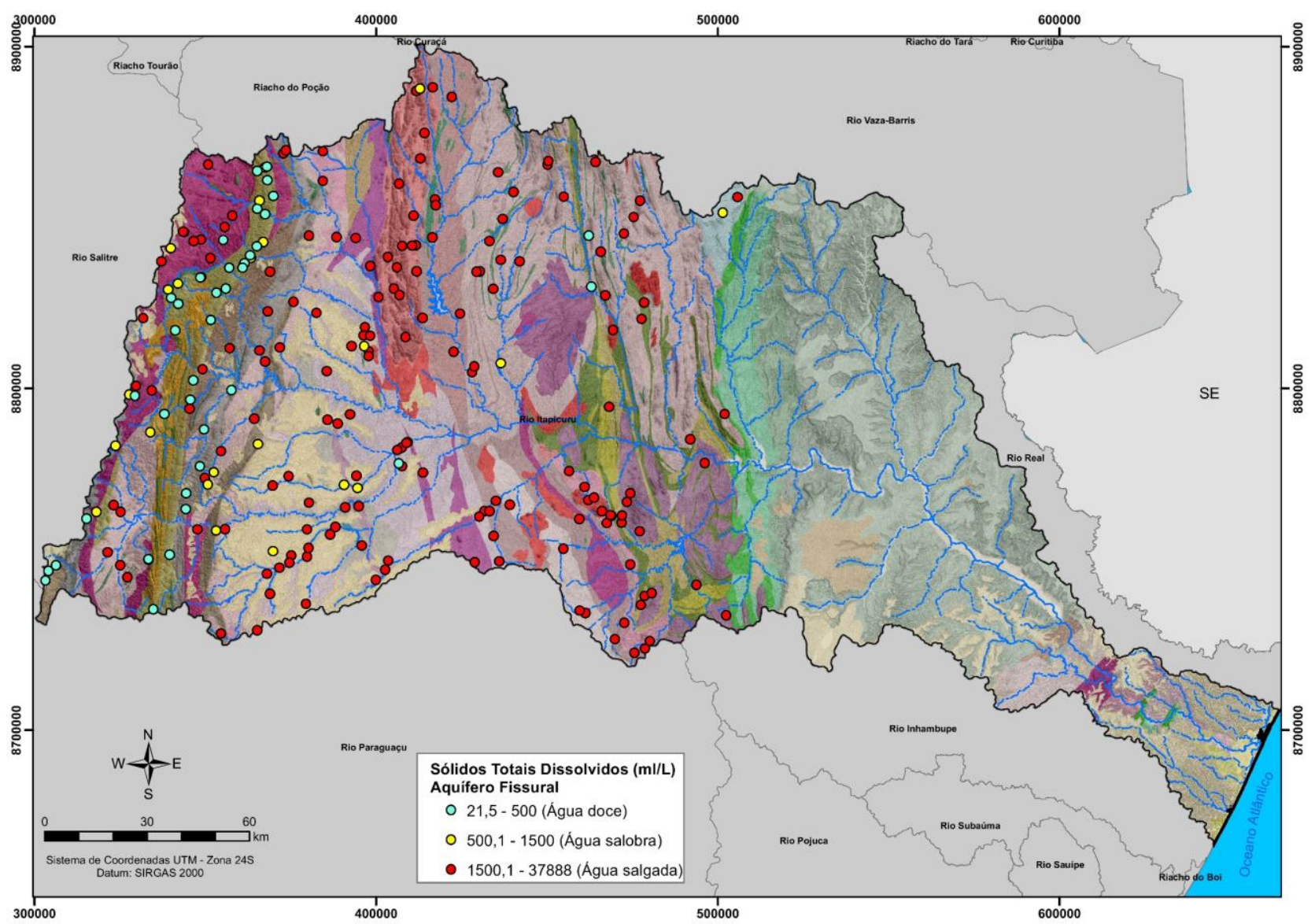

Figura 19: Distribuição espacial do STD na Bacia Hidrográfica do rio Iapicuru.

1.2.2 Diagrama de Lemoine (1954)

De acordo com esse diagrama, a maioria das águas dos aquíferos físsurais não são apropriadas para uso na irrigação, apresentando-se, em sua maioria, risco de salinização de muito alto à excepcionalmente alto, dado por $16 \%$ em C4 e $47 \%$ em C5, respectivamente (Figura 20). 


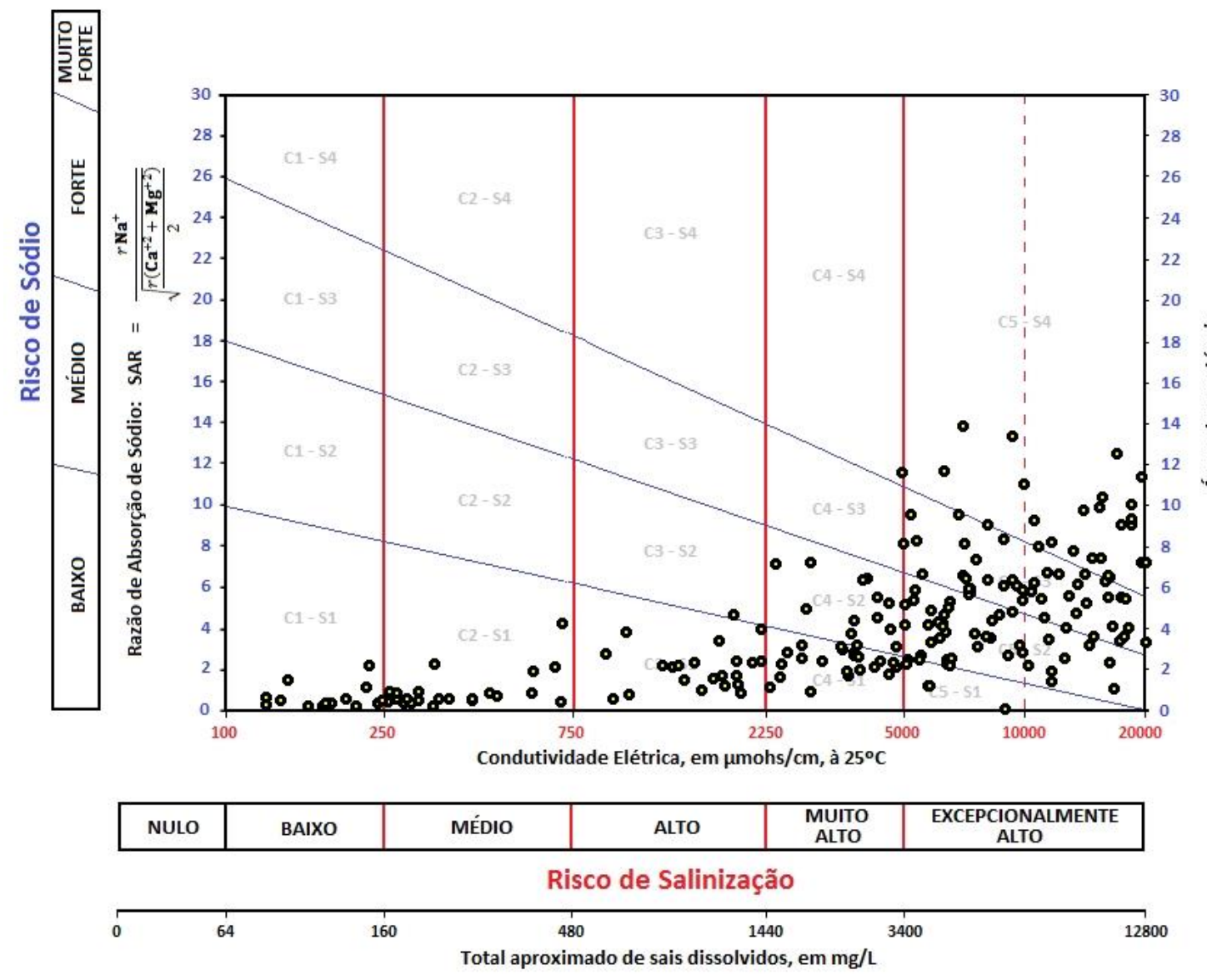

Figura 20: Classificação das águas para irrigação, segundo diagrama de Lemoine (1954).

\section{Conclusão}

A Bacia hidrográfica do rio Itapicuru ocupa aproximadamente uma área de $37.345 \mathrm{Km}^{2}$, abrangendo na sua totalidade 49 municípios. Sua hidrogeologia pode ser dividida em duas subunidades hidrogeológicas, a primeira correspondente a hidrogeologia de meios fissurais e a segunda correspondendo a meios porosos.

A unidade mais produtiva é a de meios porosos. Essa unidade também apresenta um melhor qualidade para o consumo.

\section{Referências}

BERNDTSSON, R.; Larson M. Spatial variability of infiltration in a semi-arid enviroment. Journal of Hydrology, v. 90, p. 117-133, 1987.

RADAMBRASIL, Ministério das Minas e Energia. Secretaria Geral. Projeto RADAMBRASIL. Folha SC. 24/25 Aracaju/Recife: Geologia, Geomorfologia, Pedologia, Vegetação e Uso Potencial da Terra. Rio de Janeiro, 1981. 624p. 
RPGA da Bacia do Rio Itapicurú.Programa Monitora. Programa de Monitoramento das Águas do Estado da Bahia. Secretaria do Meio Ambiente e Recursos Hídricos.

MORAIS, F. de. Infiltração - Uma variável geomorfológica. Universidade Federal do Tocantins Porto Nacional (Pesquisa na Web). Disponível em: http://periodicos.pucminas.br/index.php/geografia/article/viewFile/3753/4389, Acesso em: 10/07/2016, às 13:18h. 